\title{
IN ZAKE „EEN STEEDS DRINGENDER EISCH.”
}

Naar aanleiding van mijn onder bovenstaanden titel in de jongste aflevering van dit tijdschrift gnplaatst opstel, had ik de ear van den heer Rochussen een schrijven to ontrangen van den volgenden inhoud:

Den Heere Dr. C. A. Verrijn Stuart.

$$
\text { 's Gravenhage, } 19 \text { Juni } 1893 .
$$

WelEdol Geboren Zeer Geleerde Heer.

Met belangstelling las ik in het laatste No. van de Economist uw opstel: "Een steeds dringender eisch." De bedoelde eisch, te weten: "bij het volk het besef te wekken: denkbaar is een toestand onzer kapitalistische Maatschappij, waarin de kapitalisten de proletariërs en de arbeiders de bezittenden zullen zijn" - wordt intusschen door mij geenszins gesteld, veel minder als dringend beschouwd. Arbeiders die reeds nu tevens „bezittenden" zijn, ken ik in menigte, ja ik geloof niet dat er een enkel arbeider is zonder allo bezit. Maar wat soort wezens uwe kapitalisten-proletariërs zouden zijn, daarvan, ik beken het, kan ik mij geen voorstelling maken. Aangenomen nu dat het denkbare wezens zijn, en dat in uwe Maatschappij der toekomst alle of althans de meeste kapitalisten tot die categorie zouden hehooren, zonder uitzicht zich tot den stand der arbeiders te kunnen verheffen; aangenomen, dat zulk eene Maatschappij "denkbaar" ware, dan zou het nog de vraag zijn, of zij ook bestranbaar, en - zoo ja - deugdelijk, beter dan de tegenwoordige ware. Het antwoord op die rragen zoek ik in uw opstel te vergeefs. En in ieder geval wat kan het bloote "besef" dat eene Maatschappij op dien voet "denkbaar" is, den arbeiders wel baten?

Toelichting van die (door a gespatieerde) uitspraak zou, denk ik, velen met mij welkom zijn.

Ik verwacht ook geen heil van uw anderen, meer praktischen 
eisch, de staathuishoudkunde tot leervak der hoogere burgerscholen met 3 jarigen cursus en tot examenvak voor aspirant hulp- en hoofdonderwijzers te maken. Ik laat tal van andere en zeer gewichtige bezwaren ter zịjde, om slechts als mịne zeer besliste overtuiging te kennen te geven, dat daarvan geen vermindering, wel vermeerdering van het aantal sociaal-democratisch gezinde jongelieden en onderwijzers te verwachten is. Een enkel feit onder zeer vele, om aan te duiden waarop dat min gunstig oordeel omtrent de vermoedelijke gevolgen van uw voorstel rust. Door een ander schrijver in de Economist werd nog onlangs, herinner ik mij wel, in het laatstvorig No., uitdrukkelijk verklaard dat de onuitvoerbaarheid van het sociaal-democratisehe stelsel geenszins als bewezen kan gelden. Zoodanig scepticisme ten aanzien van de grondslagen der tegenwoordige maatschappelijke orde bij wetenschappelijke staathuishoudkundigen zal zich, in de hoofden van vele dier nienwe leerlingen en leuraren onzer wetenschap, allicbt in een warm geloof aan den sociaal-democratischen "heilstaat" omzetten.

"Gezonde economische begrippen" wenseht $u$ "bij het volk ingang to doen vinden." Als men het er nu maar over eens was, welke de gezonde economische begrippen zijn! Is het uwe bedoeling dat dit punt zal worden uitgemaakt door de overheid, in staat cn gemeente, die de leoraren aanstelt?

Eene zeer aangelegen vraag zou het voor mij zijn, of tot de gezonde begrippen ook dat van ,het volksinkomen" behoort? Er is, volgens $u$, een volksinkomen dat naar zekere regelen verdeeld wordt, "regelen die den workman onbekend zijn." Vergun mij de opmerking dat die regels evenzeer $u$ en ieder ander onbekend zijn. Om de eenvoudige reden dat zij niet bestaan: er is geen volksinkomen, en wat niet is, kan niet verdeeld worden.

Die leer van het rolks- of maatschappelijk inkomen is met de feiten in strijd. Ook in zoover, als in geen land ter wereld do vorming der bijzondere inkomsten uitsluitend door de daar geldige wetten en bestaande nationale toestanden beheerseht wordt. Ik weet niet of men zeggen $k a n$, dat dit vroeger in China het geval was. De Duitsche economen construeeren zich eene Maatschappij die met den Staat samenvalt. Mijns erachtens: eene miskenning van het grondbeginsel waarop geheel de economische wetenschap rust, en een allerongezondst begrip; want er is niets dat zoozeer het militarisme voedt en het pauperisme aankweekt, dat zoovelen tot proletariers maakt (ik bedoel ware proletariers, die niet tevens kapitalisten zijn). 
Maar or is meer. Wie zich op het standpunt plaatst, dat or een naar zekere regelen te verdeelen maatschappelijk of volksinkomen is, stemt onbewust met geheel de sociaal-democratische leer in.

Ik heb dit betoogd in het $\mathrm{Dagblad}$ van den $4 / 5$ dezer, waarvan ik mij vergun u gelijktijdig met deze letteren een ex. te doen toekomen.

En nu meen ik het recht te hebben, te verlangen dat men of het daarin geleverde betoog wederlegge, of het maatschappelijk inkomen late waar het vitsluitend thuis behoort: in de hersenschimmige wereld die de schepping is van Duitsche geleerden.

Bjjzondere prijs zou ik er op stellen, indien die wederlegging door $u$ in de Economist wierd ondernomen en tevens aan de lezers medegedeeld wierd dit schrijven dat tot UWEGZG. de eer had te richten.

Uw dienstw:

Rochussen.

De heer Rochussen bespreekt drie punten: de inhoud van den gestelten eisch is hem onduideljk, tegen uitbreiding van het onderwijs in de Staathuishoudkunde hoeft hij ernstig bezwaar, en het begrip volksinkomen acht hij in de cconomie onbruikbaar, en hen die het handhaven inconsequent voor zoover zij geen sociaaldemokraten zijn.

Het zij mij vergund op ieder dezer punten kort te antwoorden, daarbij het tweede tot het laatst bewarende.

Wat dan allereerst den inhoud van den door mij gestelden oisch betreft, zij mij de opmerking veroorloofd dat de heer Rochussen die slechts ten halve eiteert. Zonder een tockomst waarin de kapitalisten "proletariërs", en de arbeiders "de bezittenden" zullen zijn als aanstaande of sterker nog als wenschelijk voor te willen stellen, was mijn bedoeling met de door den heer Rochussen geincrimineerde paradox eenvoudig deze.

In strijd met de sociaaldemocraten on anderen die meenen, dat de bestaande ongelijkheid in welvaart een gevolg is van do. toepassing der liberaal-economische grondbeginselen, en die daarom alleen verbetering wachten van een meer of min ingrijpende herziening der grondslagen onzer maatschappelijke samenleving, ben ik van meening dat, gelijk ik vroeger gelegenheid had in dit tijdschrift uitvoeriger te betoogen, die ongelijkheid ondanks de toepassing dezer groudbeginselen is veroorzaakt door omstandigheden die ook bij de "kapitalistische" inrichting der maatschappij kunnen 
worden overwonnen. De verdeeling van het volksinkomen toch (over dit begrip zoo straks nader) is naar mijne meening in hoofdzaak cen waardekwestie. Waar nu thans, tengevolge van verschillende oorzaken, wier bespreking op dit oogenblik te ver zou afleiden, de verdeeling geschiedt ten ongunste der arbeiders, is or geen enkele logische eisch die verbiedt de mogelijkheid aan te nemen, dat bij veranderde waardeverhouding tusschen de productiefactoren, ten gevolge van steeds stijgende kapitaalvorming en geleidelijk verminderend arboidsaanbod (om slechts de hoofdvoorwaarden te noemen), het deel van den arbeider-producent in het totaalproduet eens grooter zal zijn dan dat van den kapitalist-producent. Ziedaar de bedoeling van die in mijn vorig opstel gespatieerde woorden, waarvan het mij wel eenigazins verbaast dat zij der heer Rochussen kon ontgaan.

Het besef hiervan, dat de sociale queastie kan opgelost worden met behoud der tegenwoordige grondslagen onzer samenleving, (omdat niet deze de verdeeling der goederen beheerschen, welke met behoud dier grondslagen even goed ten voordeele der arbeiders on ten nadeele der kapitalisten denkbaar is) in steeds wijder kring te verbreiden acht $\mathrm{ik}$ nog steeds dringend noodig. Het gaat toch niet aan de huidige maatschappelijke orde, in welke zoovelen bitter gebrek lijden buiten hun schuld, te handhaven, zonder dat men algemeen het besef wekt en levendig houdt, dat dit gebrek niet oorzakelijk samenhangt met de grondslagen onzer samenleving. Men kan en mag met name de sociaaldemokratie naar mijn vaste overtuiging niet langer bestrijden door alleen te wijzen op de zwakheden van haar leer. Daar naast moet kunnen aangetoond worden, dat onze tegenwoordige maatschappij in staat is de in haar bestaande ellende, voor zoover die niet van schuld het gevolg is, weg te nemen; dat zij met behoud harer grondslagen zich kan ontwikkelen tot eene, waarin de ongelijkheid die steeds zal blijven bestaan haar stuitend karakter van thans verloren heeft.

Kan men dit niet, dan is onze tegenwoordige sociale organisatie veroordeeld, en behooren allen wien de nooden des volks cen ernstig leed zijn, to streven naar een betere.

Ik ben echter nog zeer vast overtuigd dat men dit wel kan, en blijf het dringend noodig achten dat ernstig er naar worde gestreefd dit besef steeds meer ingang te doen vinden. Wat zulk besef den arbeiders baten kan? Dit, dat zij minder dan thans overgegeven aan door hen zelf onbegrepen toekomst-droomerijen, krachtig de hand slaan aan het verwezenlijken der voorwaarden 
om in de maatschappij den socialen vrede te verzekeren; en dat zij, politiek mondig geworden, met eenig oordeel kunnen overwegen de middelen, dan zeker meer nog dan thans door allerlei sociologen van beter on minder allooi het rolk aangeprezen als dienstig om tot een algemeene welvaart te geraken. Dat zij dus leeren hun toestand te verbeteren, en zich voor schade te wachten, ten nutte van de maatschappij en van hen zolven.

Ziedaar den inhoud en de gronden van hetgeen ik blijf noemen een steeds dringender eisch.

In de tweede plats acht de heer Rochussen het begrip volksinkomen een onding, dat hoe eer zoo beter uit de economische litteratuur behoort te verdwijnen, daar zij die het handhaven eigenlijk zonder het zelf te weten sociaaldemokraten zijn. De heer Rochussen verwijst bij dit punt in zijn brief naar cen hoofdartikel in het Dagblad waar hij à propos van de onvereenigbaarheid der eischen "belasting naar draagkracht" en "belasting als middel tot betere verdeeling van welvaart" deze stellingen nader ontwikkeld heeft.

Het wil mij bescheidenlijk voorkomen dat hier eenige verwarring heorscht. Wanneer men zich het volksinkomen zou denken als een tastbare eenheid, die nog wel rolgens "geldige wetten" in bijzondere inkomsten verdeeld zou worden, dan is het zeker volkomon waar, dat zoodanig volksinkomen nergens bestaat. Maar welk econoom heeft ooit in dien zin van een rolksinkomen als iets werkelijks bestaands gesproken? Het begrip volksinkomon is een abstractie meer niet, een "Gedankending", dat recht van bestaan heeft tot tijd en wijle wordt aangetoond dat het met de eischen der logica in botsing komt.

Wanneer men meent dat de verdeeling van het volksinkomen, (waaronder ik kortheidshalve hier verstaan wil de som der in een zekere periode door een volk voortgebrachte goederen) niet volgens regelen geschiedt eilieve hoe dan? Willekeurig?

Dat een zeker kapitaal op een bepaald oogenblik zooveel ronte maakt en een zeker arbeider zooveel loon, is in hoofdzaals eon gevolg van .de waarde van dat kapitaal en dien arbeidsdienst. En omtrent het oorzakelijk verband dat deze waarde beheerscht, heeft de oeconomie regelen, wetten ontdekt, die ongeschreven in de samenleving gelden, en de verdeeling der goederen beheerschen.

Het bezwaar van den heer Rochussen is mij cen woinig onbe- 
grijpelijk. Onze samenleving bestaat toch niet uit een menigte Robinson-huishoudingen, waarvan elk gehe日l zelfstandig in eigen behoeften voorziet. In samenwerking, coöperatief in ruimeren zin, geschiedt de voortbrenging, verschillende inkomsten zijn ieder een deel van een gezamenlijk gekweekt produkt. Waarom zou men zich nu niet de abstractie van een volksinkomen, alle individueele inkomens omvattend, mogen vormen? Waarom niet naast het begrip volk, welks leden niet ieder op zich zelf, maar op zoo ingewikkelde wijze hunne inkomens produceeren, het begrip volksinkomen mogen plaatsen, waar dit begrip in tal van hoofdstukken der economie (laat mij om niet te ver af te $d w a l e n$ volstaan met er twee te noemen: de leer der handelspolitiek, en de Finanzwissenschaft) zulke goede diensten bowees?

Ja maar, zegt de heer Rochussen, daarmede haalt ge het paard van Troje binnen; zoodoende behoort ge consequent althans in beginsel met de sociaal-demoncraten mee te gaan die het volksinkomen door den Staat willen doen verdeelen op een wijze die zij meer in het algemeen belang achten dan die volgens welke de verdeeling thans geschiedt.

Ik kan dit allerminst inzien, en ben voorloopig niet van plan in de rijen der collectivisten plaats te nemen. De heer Rochussen zou gelijk hebben, indien de economie zich het volksinkomen dacht als iets wat reeds thans, na als eenheid bijeen gebracht te zijn, door zekere organen en volgens zekere regelen werd verdeeld. Doch ik zeide reeds dat nooit het begrip volksinkomen zoo is opgevat door de economie.

Ik kan dan ook volstrekt niet toegeren dat het onlogisch of inconsequent zou zijn, wanneer ik meen, dat de maatschappij en haar leden 't best gediend zijn, indien de verdecling van de vruchten der gezamenlijke productie geschiedt volgens de ongeschreven wetten die haar thans beheerschen, en niet volgens regelon door den Staat te stellen.

Deze verdeeling geschiedt thans in hoofdzak rechtmatig; dat $z i j$ niet gelijkmatiger plaats vindt is een betreurd gevolg van oorzaken die de grondslagen onzer samenleving niet reken. Ziedaar de kern van mijn betoog die ik ook nu nog meen te moeten handhaven.

Het besef hiervan bij ons volk meer ingang te doen vinden noemde ik in mijn opstel en hierboven een steeds dringender eisch, en het middel om aan dezen te voldoen zag ik in meor algemeen onderwijs in de economie. De heer Rochussen acht uit- 
breiding van het onderwijs in de staathuishoudkunde volstrekt ongewenseht.

Dat zoodanige uitbreiding bezwaren heeft, ernstige bezwaren zelfs wil ik gaarne erkennen. Toch gelonf ik dat zij die deze overwegend achten, zouden topnen al zeer weinig vertrouwen te bezitten in de deugdelijkheid hunner overtuiging.

$\mathrm{Ja}$, wanneer men meent, dat bij ernstigen eerlijken strijd de economie het tegen het collectivisme moet afleggen, kan ik het begrijpen dat men vreest voor meer algemeene economische ontwikkeling. Men zal, op eigen kracht niet recht meer vertrouwende, niet nog vrijwillig den vijand van wapenen roorzien. Maar allen die vertrouwen in de superioriteit der "orthodoxe" economie boven het collectivisme kunnen dunkt mij samengaan in den eisch dat de eerste meer algemeen worde geleerd. Men kan op dit standpunt dunkt mij niets liever willen, dan zoovelen mogelijk tut kennismaking met de economie te brengen, den strijd op te zoeken on zoo te trachten een communis opinio te maken van hetgeen men zelf eerlijk voor waar houdt.

Recht voor Allen plaatst als motto boven elke nummer deze uitspraak van Heine: „de hedendaagsche maatschappij verdedigt zich slechts uit platte noodzakelijkhoid, zonder geloof in haar goed recht, ja zonder achting voor zichzelve, op dezelfde manier als die oudere maatschappij, wier bouwvallige balken ineenstortten, toen de zoon des timmermans optrad". Het eenig middel om aan deze gevaarlijke uitspraak zelfs geen schijn van waarheid te laten schijnt mij een zoo algemeen mogelijk onderwijs omtrent de geschiodenis en de inrichting onzer maatschappelijke samenleving.

Zelfs waar men eenigen twijfel koesteren mocht aan de waarheid der tot dusver gehuldigde opvatting van hetgeen de voorwaarden van volkswelvaart zijn. moet men, naar 't mij voorkomt verlangen dat zoo spoedig mogelijk een gemeenschappelijke overtuiging zich vestige omtrent de al of niet wenschelijkheid van handhaving der tegenwoordige grondslagen onzer samenleving. Een toestand al thans bestaat, waarbij een belangrijk deel van ons volk als onrecht roelt hetgeen door anderen noodzadelijk en heilzaam wordt geacht, kan dunkt mij niemand willen bestendigen. De laatsten moeten of eerlijk de vlag strijken en de wapenen neerleggen, of ernstig er naar streven ook de anderen te doordringen van de gronden hunner overtuiging.

Waar ik het eerste natuurlijk niet begeeren kan, gaf ik de middelen aan de hand, die naar mijne meening dienen kunnen om het laatste te bevorderen. 
Uitbreiding van het economisch onderwijs op de burgerscholen, ${ }^{1}$ ) jnvcering van de Staathuishoutkunde als examenvak voor de aanstaande onderwijzers, en cursussen voor kleine kringen van arbeiders ziedaar hetgeen ik dringend noodig blijf achten.

Zeker, het is een moeilijk werk aan arbeiders een cursus over staathuishoudkunde te geven; het gevaar bestaat dat sommigen na oppervlakkige kennismaking met deze wetenschap zich geJoovig aan de sociaaldemokratie zullen gewonnen geven. Maar men mag niet vergeten dat, naast veel oppervlakkigheid en gebrek aan ernst, vaak onder de arbeiders leeft een nuchter gezond verstand, dat wikt en weegt, en niet aanstonds alles goud acht wat blinkt. De besten van hen, niet in staat om zelfstandig kritische studien te maken op het gebied der samenleving, zullen dankbaar de gelegenheid aangrijpen om onder leiding van anderen dit te doen.

Dezen te brengen tot zelfstandig economisch nadenken en hen in staat te stellen dit met eenigen vrucht te doen acht ik op grond der ervaringen met mịjn cursus opgedaan volstrekt niet. onmogelijk. En dit alleen moet voorloopig het doel zijn van cursussen als de bedoelde; men mag immers verwachten dat hetgeen dezulken geleerd hebben in wijder kring vrucht dragen mal.

Op deze wijze hoop ik, dat als gevolg van een krachtiger

1) Het Vaderland dat tot mijn voldoening mijn beschouwiugen deelde noemde in een bespreking van mija opstel in bet No. van $25 \mathrm{Juni}$ 1.l. vanst de hoogere burgerscholev ook de gymnasia als inrichtingen watr luet aan economisch ouderwijs een behoorlijke plats zou wenschen ingernimd te zien. I $k$ kan $m i j$ met deze loevoeging gebeel vereenigen. Afgezien van het betrekkelijk klein antal toekomslige natuur-philosofen en litteratoren dat de gymnusia benoekt, schijnt mij voor annstunnde medici, theologen en juristen zulk onderwijs zeer gewenscht. De beide cersten zullen in hun lateren praktischen werkkring over allerlei sociale vrigen zich een oordeel moeten vormen, beiden kowen zij litter net de wooden des volks op het nauwst in aanraking. Eenige studic van de voorwanten der economisehe ontwikkeling van de mantschappij is dan rom, nog ufgezien van andere voordeelen, voor hen zeker wenschelijk. En wan an vutuurlijk slechts een uiterst kleive miuderbeid van ben asu de academie vrijwillig colleges over economie volgt, schijnt het gymusium aungewezen om in deze behoefte te voorzien.

Wut de juristen betreft, voor dezen si de economie an de universitrit wel een eximenvak, dat echter zonder twijfel nog beter tot zijn recht zou komeu wanueer op het gymnasium reeds de grondsligen waren gelegd. 


\section{2}

optreden der Staathuishoudkunde, gezonde economische denkbeelden bij bet volk ingang zullen vinden. Dat de administratiove autoriteit naar mijne meening zou hebben uit te maken wat gezonde economische begrippen zijn, zal de heer Rochussen wel niet gelooven. Een wetenschap van hooger hand vastgesteld is een ongerijmdheid. Alleen het intellect der beoefenaars vall de economie doet hier uitspraak; dat deze bij ernstig en eerlijk nadenken niet ton gunste der sociaaldemokratie kan uitvallen is mịn stellige verwachting.

Dr. C. A. Verrijn Stidart. 